\title{
Characteristics of Breast Cancer Patients Who Refuse Surgery
}

\author{
DAVID J. RESTREPO ${ }^{1}$, ANDREA SISTI ${ }^{1}$, DANIEL BOCZAR ${ }^{1}$, MARIA T. HUAYLLANI ${ }^{1}$, \\ JENNIFER FISHE ${ }^{2}$, EMMANUEL GABRIEL ${ }^{3}$, SARAH A. MCLAUGHLIN ${ }^{3}$, \\ SANJAY BAGARIA ${ }^{3}$, AARON SPAULDING ${ }^{4}$, BRIAN D. RINKER ${ }^{1}$ and ANTONIO J. FORTE ${ }^{1}$ \\ ${ }^{1}$ Division of Plastic Surgery and Robert D. and Patricia E. Kern Center for the \\ Science of Health Care Delivery, Mayo Clinic, Jacksonville, FL, U.S.A.; \\ ${ }^{2}$ Department of Emergency Medicine \& Center for Data Solutions, \\ University of Florida College of Medicine, Jacksonville, FL, U.S.A.; \\ ${ }^{3}$ Department of Surgery, Mayo Clinic, Jacksonville, FL, U.S.A.; \\ ${ }^{4}$ Department of Health Science Research, Mayo Clinic, Jacksonville, FL, U.S.A.
}

\begin{abstract}
Aim: This study describes the demographic, socioeconomic, and tumor-specific characteristics of patients who refuse breast cancer surgery. Materials and Methods: This is a retrospective study of breast cancer patients from 2004-2015 captured by the National Cancer Data Base. Demographic, socioeconomic, and tumor-specific predictors were compared between patients who refused breast cancer surgery versus those who agreed to surgery, using bivariate and multivariate models. Results: A total of 2,445,870 patients met the inclusion criteria. On multivariate analysis, black and Asian patients had higher odds of refusing surgical treatment compared to whites $(O R=2.16, C I=2.05$ $2.28, \quad p<0.001), \quad(O R=1.58, \quad C I=1.41-1.76, \quad p<0.001)$, respectively. Moreover, patients with government insurance $(O R=1.97, C I=1.86-2.09, p<0.001)$ and uninsured patients $(O R=3.91, C I=3.50-4.36, p<0.001)$ were found to have higher odds of surgical treatment refusal when compared to patients with private insurance. Conclusion: Specific demographic and disease-specific characteristics are related to refusing potentially life-saving breast cancer surgery.
\end{abstract}

In $2019,1,762,450$ new breast cancer cases and 606,880 cancer deaths are projected to occur in the United States (1). Furthermore, breast cancer is the most common cancer in women and second most common cause of cancer death (1). Refusing surgery is a brave decision that has a deleterious effect on breast cancer mortality and is more commonly related to advanced disease, which has a poor prognosis (2). Previous studies focused on patients with pancreatic cancer who refused

Correspondence to: Antonio Jorge Forte, MD, Ph.D., Mayo Clinic Florida, 4500 San Pablo Road, Jacksonville, Florida 32224, U.S.A. Tel: +1 9049532073, e-mail: ajvforte@yahoo.com.br

Key Words: Breast cancer, surgery refusal. surgery demonstrated that there were disparities in the refusal of cancer-directed surgery and that several variables, such as insurance, sex, and race, were independently associated to this outcome $(3,4)$. However, studies on breast cancer have not elucidated groups likely to refuse surgical treatment. Therefore, this study's objective was to describe the demographic, socioeconomic, and tumor-specific characteristics related to surgery refusal in the United States (US) breast cancer population using the National Cancer Database (NCDB).

\section{Materials and Methods}

This study was a retrospective cohort analysis of the NCDB, which is a program of the Commission on Cancer of the American College of Surgeons and the American Cancer Society. NCDB captures approximately $70 \%$ of newly diagnosed US cancer patients (5). This study was exempt from Institutional Board Review due to the deidentified data.

Women and men diagnosed with breast cancer (disease stages I, II, and III) between January 1st, 2004 and December 31st, 2015 were included in the study. Patients who were diagnosed at autopsy or who were only reported to have breast cancer on death certificate, but not on clinical record were excluded. Patients with stage IV disease were also excluded because this group typically is not offered surgical treatment per guidelines (6). The inclusion and exclusion criteria are outlined in Figure 1.

The NCDB variable "Reason for no Surgery" was used to identify the cohort of patients who refused surgery even when it was recommended by the treating physician. Patients were filtered and separated into two groups for comparison: patients who refused surgery $v s$. patients who received surgery.

The following patient-specific variables abstracted: age, gender, race, insurance status, income, education, population density and facility type. Disease-specific characteristics abstracted include: disease behavior, disease stage, histology, tumor size, laterality, and triple-negative disease assessment. These covariates were selected because they characterize the patient- and disease-specific variables that could influence the decision to refuse surgical treatment for breast cancer. 
Patient- and disease-specific characteristics were compared between patients who had surgery versus patients who refused surgery. The $\chi^{2}$ test was used to compare explanatory variables and the rate of surgery treatment refusal. A multivariate regression model was created to adjust for potential confounders, patientspecific characteristics and disease-specific characteristics affected the odds of refusing surgical treatment. Patients with any missing data were excluded from regression models. Significance was set at a $p<0.05$. Statistical analysis was performed using SPSS 25.0 statistical software (SPSS Inc., Chicago, IL, USA).

\section{Results}

Our NCDB search identified 2,445,870 patients diagnosed with breast cancer during the study period, 2,259,024 of whom met inclusion criteria. The $\chi^{2}$ test revealed that demographic characteristics had an association with surgical treatment refusal (Table I). Patients who were 80 years of age or older were associated with surgery refusal $(p<0.001)$ when compared to patients who were younger. Furthermore, black race had a significant association with treatment refusal $(p<0.001)$, while white patients were less prone to refuse treatment. Government insurance and patients with no insurance were associated to surgery refusal $(p<0.001)$ when compared to patients with private insurance.

Tumor-specific characteristics were also found to influence treatment refusal (Table II). Invasive behavior and tumor stages II and III showed a positive association with treatment refusal $(p<0.001)$. On histology examination, ductal carcinoma and mixed carcinomas $(p<0.001)$ had a negative association with surgical refusal $(p<0.001)$, while lobular carcinomas showed a significant association with surgical treatment refusal $(p<0.001)$. Laterality of the tumor showed no significant difference. Patients who refused breast cancer surgery had a lower rate of triple-negative breast cancer $(p<0.001)$ when compared to patients who accepted treatment.

When adjusted for confounders (Table III), our results showed that patients aged 60 to 80 years $(\mathrm{OR}=1.2$; $\mathrm{CI}=1.12$ $1.28)$ and more than 80 years $(\mathrm{OR}=8.14 ; \mathrm{CI}=7.60-8.72)$ had higher odds of refusing surgical treatment than patients aged 40 to 60 years. Women $(\mathrm{OR}=1.48 ; \mathrm{CI}=1.48-1.85)$ were found to have higher odds of refusing breast cancer surgery than men with breast cancer. Black $(\mathrm{OR}=2.30 ; \mathrm{CI}=2.17-2.43)$ and Asian (OR=1.62; $\mathrm{CI}=1.44-1.82)$ patients were also found to have higher odds of refusing surgical treatment, compared to white patients. No significant difference was found in Native American patients when compared to white patients. Moreover, patients with government insurance $(\mathrm{OR}=1.97$; $\mathrm{CI}=1.85-2.09)$ and uninsured patients $(\mathrm{OR}=3.91 ; \mathrm{CI}=3.46$ 4.42) were found to have higher odds of surgical treatment refusal when compared to patients with private insurance. Also, we found that patients that live in a zip code in which $<7 \%$ of the population did not graduate high school $(\mathrm{OR}=1.11 ; \mathrm{CI}=0.85-0.98)$ have higher odds of breast cancer

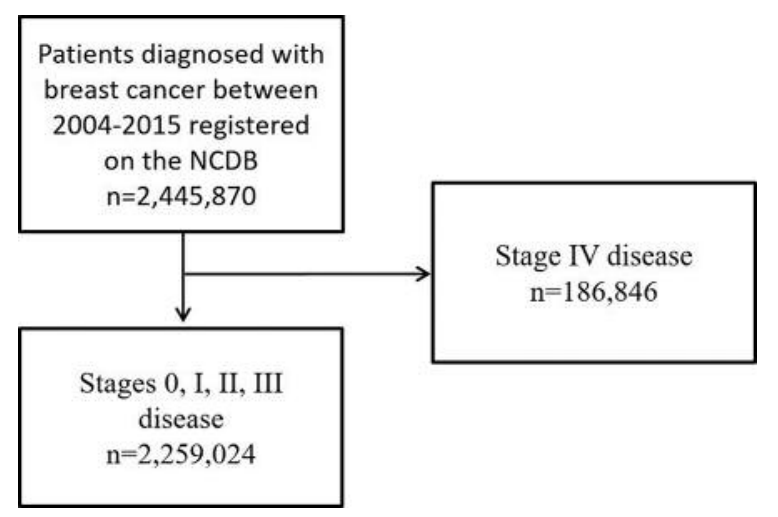

Figure 1. Inclusion and exclusion criteria. NCDB, National Cancer Database.

surgery refusal than patients that live in a zip code in which $>21 \%$ of the population did not graduate high school. Patients with breast cancer stages II ( $\mathrm{OR}=1.88$; $\mathrm{CI}=1.45$ 2.44) and III ( $\mathrm{OR}=2.99 ; \mathrm{CI}=2.30-3.89)$ were more likely to refuse surgical treatment when compared to stage 0 patients. When compared to triple-negative breast cancer, patients with non-triple-negative disease had higher odds of refusing breast cancer surgery $(\mathrm{OR}=1.81 ; \mathrm{CI}=1.64-2.00)$.

\section{Discussion}

Our study results show that there is a number of patient and disease characteristics associated with refusing surgical treatment. These characteristics include higher age at diagnosis, female gender, black and Asian race, government or no insurance, living in zip codes in which a higher percentage of the population did not graduate high school, disease stages II and III, adenocarcinomas, and non-triplenegative breast cancer. It has been shown that refusing surgery for breast cancer, at any stage, can significantly decrease survival and therefore, it is important to understand what factors may impact a patient's choice of refusing surgery (2).

Our findings that medical treatment is more often refused by patients with higher age have been also found in other cancer studies $(7,8)$. Previous studies have demonstrated that higher age independently increases the odds of refusing cancer surgery $(2,9,10)$. This could be caused by different factors, such as shorter life expectancy, higher likelihood of surgical adverse events, or higher rate of comorbidities. It has also been demonstrated that elderly patients are less likely to get surgery for cancer than younger patients (11).

An interesting finding of this study is that women have independently higher odds of refusing breast cancer surgery than men. Although not easy to explain, it could be due to 
Table I. Chi-square analysis of demographic characteristics.

\begin{tabular}{|c|c|c|c|c|c|}
\hline \multirow[b]{2}{*}{ Variable } & \multicolumn{2}{|c|}{ Treated } & \multicolumn{2}{|c|}{$\begin{array}{l}\text { Refused } \\
\text { treatment }\end{array}$} & \multirow[b]{2}{*}{$p$-Value } \\
\hline & $\mathrm{N}$ & $\%$ & $\mathrm{~N}$ & $\%$ & \\
\hline Age & & & & & $<0.001$ \\
\hline $18-40$ years & 101805 & 4.5 & 164 & 1.6 & \\
\hline $40-60$ years & 972155 & 42.9 & 2072 & 20.7 & \\
\hline $60-80$ years & 992631 & 43.8 & 3062 & 30.5 & \\
\hline$>80$ years & 200420 & 8.8 & 4732 & 47.2 & \\
\hline Total & 2267011 & 100.00 & 10030 & 100.00 & \\
\hline Gender & & & & & 0.904 \\
\hline Male & 19862 & 0.9 & 89 & 0.9 & \\
\hline Female & 2247149 & 99.1 & 9941 & 99.1 & \\
\hline Total & 2267011 & 100.0 & 10030 & 100.0 & \\
\hline Race & & & & & $<0.001$ \\
\hline White & 1904096 & 85.50 & 7448 & 75.80 & \\
\hline Black & 243873 & 10.90 & 2012 & 20.50 & \\
\hline Asian & 73648 & 3.30 & 346 & 3.50 & \\
\hline Native American & 5677 & 0.30 & 24 & 0.20 & \\
\hline Total & 2227294 & 100.00 & 9830 & 100.00 & \\
\hline Insurance status & & & & & $<0.001$ \\
\hline Private & 1225996 & 55.00 & 2218 & 22.50 & \\
\hline Government & 961410 & 43.10 & 7282 & 73.90 & \\
\hline Not insured & 40988 & 1.80 & 355 & 3.60 & \\
\hline Total & 2228394 & 100.00 & 9855 & 100.00 & \\
\hline Average income in zip code & & & & & $<0.001$ \\
\hline Less than $\$ 38,000$ & 323536 & 14.4 & 1905 & 19.1 & \\
\hline$\$ 38,000 \$ 47,999$ & 859538 & 38.2 & 3232 & 32.5 & \\
\hline$\$ 48,000 \$ 62,999$ & 597992 & 26.6 & 2581 & 25.9 & \\
\hline$\$ 63,000+$ & 468077 & 20.8 & 2240 & 22.5 & \\
\hline Total & 2249143 & 100.0 & 9958 & 100.0 & \\
\hline$\%$ with no HSD in zip code & & & & & $<0.001$ \\
\hline $21 \%$ or more & 317605 & 14.1 & 1567 & 15.7 & \\
\hline $13-20.9 \%$ & 659225 & 29.3 & 2534 & 25.4 & \\
\hline $7-12.9 \%$ & 747453 & 33.2 & 3312 & 33.3 & \\
\hline Less than $7 \%$ & 525788 & 23.4 & 2546 & 25.6 & \\
\hline Total & 2250071 & 100.0 & 9959 & 100.0 & \\
\hline Population density & & & & & $<0.001$ \\
\hline Metropolitan & 1910033 & 86.80 & 8621 & 88.30 & \\
\hline Urban & 257411 & 11.70 & 1028 & 10.50 & \\
\hline Rural & 32508 & 1.50 & 118 & 1.20 & \\
\hline Total & 2199952 & 100.00 & 9767 & 100.00 & \\
\hline Facility type & & & & & $<0.001$ \\
\hline Academic/Research* & 657054 & 30.30 & 3098 & 31.40 & \\
\hline Comprehensive community* & 1047765 & 48.40 & 4409 & 44.70 & \\
\hline Community* & 217882 & 10.10 & 1178 & 11.90 & \\
\hline Integrated network* & 242505 & 11.20 & 1181 & 12.00 & \\
\hline Total & 2165206 & 100.00 & 9866 & 100.00 & \\
\hline Charlson-Deyo score & & & & & $<0.001$ \\
\hline No Comorbidity & 1926315 & 85.40 & 8162 & 83.00 & \\
\hline Score 1 & 279551 & 12.40 & 1236 & 12.60 & \\
\hline Score 2 or more & 48667 & 2.20 & 441 & 4.50 & \\
\hline Total & 2254533 & 100.00 & 9839 & 100.00 & \\
\hline
\end{tabular}

HSD, High school diploma. *Cancer Program.

the deformity and greater psychological impact that mastectomy can have on women when compared to men. A previous study on patients with resectable pancreatic cancer
Table II. Chi-square analysis for disease-specific characteristics.

\begin{tabular}{|c|c|c|c|c|c|}
\hline \multirow[b]{2}{*}{ Variable } & \multicolumn{2}{|c|}{ Treated } & \multicolumn{2}{|c|}{$\begin{array}{l}\text { Refused } \\
\text { treatment }\end{array}$} & \multirow[b]{2}{*}{$p$-Value } \\
\hline & $\mathrm{N}$ & $\%$ & $\mathrm{~N}$ & $\%$ & \\
\hline Behavior & & & & & $<0.001$ \\
\hline In situ & 456720 & $21.00 \%$ & 1579 & $15.70 \%$ & \\
\hline Invasive & 1718396 & $79.00 \%$ & 8447 & $84.30 \%$ & \\
\hline Total & 2175116 & $100.00 \%$ & 10026 & $100.00 \%$ & \\
\hline Stage & & & & & $<0.001$ \\
\hline Stage 0 & 471464 & $21.70 \%$ & 1613 & $16.10 \%$ & \\
\hline Stage I & 945658 & $43.50 \%$ & 2770 & $27.60 \%$ & \\
\hline Stage II & 568330 & $26.10 \%$ & 3673 & $36.60 \%$ & \\
\hline Stage III & 189664 & $8.70 \%$ & 1970 & $19.60 \%$ & \\
\hline Total & 2175116 & $100.00 \%$ & 10026 & $100.00 \%$ & \\
\hline Histology & & & & & $<0.001$ \\
\hline Papillary & 8064 & $0.40 \%$ & 76 & $0.80 \%$ & \\
\hline Squamous & 766 & $0.00 \%$ & 3 & $0.00 \%$ & \\
\hline Ductal & 1477737 & $67.90 \%$ & 6224 & $62.10 \%$ & \\
\hline Adenocarcinoma & 5775 & $0.30 \%$ & 144 & $1.40 \%$ & \\
\hline Lobular & 206186 & $9.50 \%$ & 1189 & $11.90 \%$ & \\
\hline Mixed & 273980 & $12.60 \%$ & 879 & $8.80 \%$ & \\
\hline Inflammatory & 4776 & $0.20 \%$ & 75 & $0.70 \%$ & \\
\hline Paget & 6520 & $0.30 \%$ & 39 & $0.40 \%$ & \\
\hline Phyllodes & 2521 & $0.10 \%$ & 5 & $0.00 \%$ & \\
\hline Others & 188791 & $8.70 \%$ & 1392 & $13.90 \%$ & \\
\hline Total & 2175116 & $100.00 \%$ & 10026 & $100.00 \%$ & \\
\hline Tumor size & & & & & $<0.001$ \\
\hline$<2 \mathrm{~cm}$ & 26382 & $1.20 \%$ & 96 & $1.00 \%$ & \\
\hline $2-4.9 \mathrm{~cm}$ & 141316 & $6.50 \%$ & 213 & $2.10 \%$ & \\
\hline$\geq 5 \mathrm{~cm}$ & 2007418 & $92.30 \%$ & 9717 & $96.90 \%$ & \\
\hline Total & 2175116 & $100.00 \%$ & 10026 & $100.00 \%$ & \\
\hline Laterality & & & & & 0.595 \\
\hline Right & 1070460 & $49.30 \%$ & 4897 & $49.00 \%$ & \\
\hline Left & 1102797 & $50.70 \%$ & 5099 & $51.00 \%$ & \\
\hline Total & 2173257 & $100.00 \%$ & 9996 & $100.00 \%$ & \\
\hline Triple-negative & & & & & $<0.001$ \\
\hline Triple-negative & 108460 & $5.00 \%$ & 419 & $4.20 \%$ & \\
\hline Non-triple-negative & 804542 & $37.00 \%$ & 4579 & $45.70 \%$ & \\
\hline Unknown & 1262114 & $58.00 \%$ & 5028 & $50.10 \%$ & \\
\hline Total & 2175116 & $100.00 \%$ & 10026 & $100.00 \%$ & \\
\hline
\end{tabular}

showed that women had higher odds of refusing surgery $(\mathrm{OR}=1.52 ; 95 \% \mathrm{CI}=1.33-1.73)$ when compared to men (3). Additionally, previous research has identified that body disfigurement caused by the surgery can affect the psychological state of female breast cancer patients $(12,13)$.

In our study, when compared to white patients, black and Asian patients were shown to have an independently higher risk of refusing surgery when diagnosed with breast cancer. There may be cultural or access to care components secondary to socioeconomic disparities (14). Furthermore, studies have reported independently increased odds of refusing cancer-directed surgery in black and Asian patients in pancreatic, breast, and hepatocellular carcinomas $(2,3,10)$. 
Table III. Odds of refusing breast cancer surgery.

\begin{tabular}{|c|c|c|c|c|}
\hline \multirow[b]{2}{*}{ Variables } & \multirow[b]{2}{*}{ OR } & \multicolumn{2}{|c|}{$95 \% \mathrm{CI}$} & \multirow[b]{2}{*}{$p$-Value } \\
\hline & & Lower & Upper & \\
\hline \multicolumn{5}{|l|}{ Age } \\
\hline $40-60$ years & & & & 0 \\
\hline $60-80$ years & 1.2 & 1.124 & 1.282 & $<0.001$ \\
\hline$>80$ years & 8.139 & 7.596 & 8.721 & $<0.001$ \\
\hline \multicolumn{5}{|l|}{ Gender } \\
\hline Male & & & & 0 \\
\hline Female & 1.482 & 1.189 & 1.847 & $<0.001$ \\
\hline \multicolumn{5}{|l|}{ Race } \\
\hline White & & & & 0 \\
\hline Black & 2.296 & 2.167 & 2.432 & $<0.001$ \\
\hline Asian & 1.622 & 1.444 & 1.823 & $<0.001$ \\
\hline Native American & 1.313 & 0.843 & 2.043 & 0.228 \\
\hline \multicolumn{5}{|l|}{ Insurance status } \\
\hline Private & & & & 0 \\
\hline Government & 1.966 & 1.848 & 2.092 & $<0.001$ \\
\hline Not insured & 3.911 & 3.463 & 4.416 & $<0.001$ \\
\hline \multicolumn{5}{|l|}{ Average income in zip code } \\
\hline Less than $\$ 38,000$ & & & & 0 \\
\hline$\$ 38,000 \$ 47,999$ & 0.821 & 0.755 & 0.893 & $<0.001$ \\
\hline$\$ 48,000 \$ 62,999$ & 0.852 & 0.79 & 0.918 & $<0.001$ \\
\hline$\$ 63,000+$ & 0.913 & 0.851 & 0.98 & 0.012 \\
\hline \multicolumn{5}{|l|}{$\%$ with no HSD in zip code } \\
\hline $21 \%$ or more & & & & 0 \\
\hline $13-20.9 \%$ & 1.222 & 1.119 & 1.335 & $<0.001$ \\
\hline $7-12.9 \%$ & 1.205 & 1.117 & 1.301 & $<0.001$ \\
\hline Less than $7 \%$ & 1.105 & 1.03 & 1.186 & 0.005 \\
\hline \multicolumn{5}{|l|}{ Population density } \\
\hline Metropolitan & & & & 0 \\
\hline Urban & 0.881 & 0.82 & 0.947 & 0.001 \\
\hline Rural & 0.776 & 0.641 & 0.939 & 0.009 \\
\hline \multicolumn{5}{|l|}{ Facility type } \\
\hline Academic/Research Program & & & & 0 \\
\hline Comprehensive Community* & 0.838 & 0.797 & 0.88 & $<0.001$ \\
\hline Community* & 0.942 & 0.876 & 1.014 & 0.11 \\
\hline Integrated network* & 0.939 & 0.875 & 1.009 & 0.086 \\
\hline
\end{tabular}

\begin{tabular}{|c|c|c|c|c|}
\hline \multirow[b]{2}{*}{ Variables } & \multirow[b]{2}{*}{ OR } & \multicolumn{2}{|c|}{$95 \% \mathrm{CI}$} & \multirow[b]{2}{*}{$p$-Value } \\
\hline & & Lower & Upper & \\
\hline \multicolumn{5}{|l|}{ Charlson-Deyo score } \\
\hline No comorbidity & & & & 0 \\
\hline Score $=1$ & 0.732 & 0.688 & 0.78 & $<0.001$ \\
\hline Score $=2$ or more & 1.233 & 1.116 & 1.363 & $<0.001$ \\
\hline \multicolumn{5}{|l|}{ Behavior } \\
\hline In situ & & & & 0 \\
\hline Invasive & 0.73 & 0.562 & 0.949 & 0.019 \\
\hline \multicolumn{5}{|l|}{ Stage } \\
\hline Stage 0 & & & & $<0.001$ \\
\hline Stage I & 0.867 & 0.668 & 1.124 & 0.281 \\
\hline Stage II & 1.877 & 1.446 & 2.435 & $<0.001$ \\
\hline Stage III & 2.994 & 2.302 & 3.894 & $<0.001$ \\
\hline \multicolumn{5}{|l|}{ Histology } \\
\hline Papillary & & & & 0 \\
\hline Squamous & 0.293 & 0.071 & 1.203 & 0.088 \\
\hline Intraductal & 0.702 & 0.549 & 0.897 & 0.005 \\
\hline Adenocarcinoma & 3.174 & 2.338 & 4.309 & $<0.001$ \\
\hline Lobular & 0.811 & 0.631 & 1.043 & 0.103 \\
\hline Mixed & 0.542 & 0.421 & 0.699 & $<0.001$ \\
\hline Inflammatory & 1.658 & 1.17 & 2.35 & 0.004 \\
\hline Angiomyosarcoma & 0.847 & 0.564 & 1.273 & 0.425 \\
\hline Paget & 0.43 & 0.173 & 1.073 & 0.071 \\
\hline Others & 1.317 & 1.025 & 1.692 & 0.031 \\
\hline \multicolumn{5}{|l|}{ Tumor size } \\
\hline$<2 \mathrm{~cm}$ & & & & 0 \\
\hline $2-4.9 \mathrm{~cm}$ & 0.471 & 0.362 & 0.614 & $<0.001$ \\
\hline$\geq 5 \mathrm{~cm}$ & 1.028 & 0.821 & 1.286 & 0.812 \\
\hline \multicolumn{5}{|l|}{ Laterality } \\
\hline Right & & & & 0 \\
\hline Left & 0.993 & 0.953 & 1.036 & 0.754 \\
\hline \multicolumn{5}{|l|}{ Triple-negative } \\
\hline Triple-negative & & & & 0 \\
\hline Non-triple-negative & 1.737 & 1.561 & 1.932 & $<0.001$ \\
\hline Unknown & 1.185 & 1.064 & 1.319 & 0.002 \\
\hline
\end{tabular}

Multivariate analysis for odds of refuse treatment. HSD, High school diploma. * Cancer Program.

Another important study finding is that patients with no insurance or those with government insurance had independently increased odds of refusing breast cancer surgery. This result is supported by Gaitanidis and colleagues (2) who performed a study using the Surveillance Epidemiology and End Results (SEER) database in which the lack of insurance was found to increase the odds of surgery refusal $(\mathrm{OR}=2.11 ; 95 \% \mathrm{CI}=1.59-2.8 ; p<0.001)(2)$. Tohme and colleagues (3), using the NCDB, found that patients with resectable pancreatic cancer were more likely to refuse surgery when they had government insurance $(\mathrm{OR}=2.75 ; 95 \% \mathrm{CI}=1.54-4.92)$ when compared to patients with private insurance (3). Further health economic analysis is required to understand the real or perceived economic impact of breast cancer surgery on patients with government or without insurance options.

Higher stage of disease was found to be an important risk factor for refusing breast cancer surgery. Multiple reasons may be driving this situation. Patients who have lower survival chances might consider that surgery will decrease their quality of life and decide not to have it. Also, higher stage of disease could imply a bigger surgical resection, which would increase cosmetic deformity, and patients might consider this unacceptable. Patients with hepatocellular carcinoma have also been shown to increase surgery refusal at higher stages (10). However, prostate cancer patients with higher stage of disease have been reported to embrace surgical treatment more often (9). 
Our study is not without limitations. Our analysis was conducted using the NCDB because it encompasses approximately $70 \%$ of all the cancer population in the US; however, due to the nature of large national databases, the fidelity of the information can be affected by incorrect or incomplete reports. Furthermore, the number of patients who refused surgery was considerably smaller than the number of patients who refused treatment. However, the large number of patients included in our study allows us to perform an analysis that is comparable to the United States cancer population and draw conclusions.

In conclusion, this study describes demographic and disease-specific characteristics related to breast cancer surgery refusal, which could be of immediate use to clinicians counseling selected populations. Further studies are needed to elucidate the underlying reasons for surgery refusal in the identified demographic and disease-specific populations.

\section{Authors' Contributions}

All Authors contributed to the study design, commented on previous versions of the manuscript, read and approved the final manuscript. Material preparation, data collection and analysis were performed by DJR, ACS and AJF. The first draft of the manuscript was written by DJR and DB.

\section{Funding}

This study was supported, in part, by the Mayo Clinic Robert D. and Patricia E. Kern Center for the Science of Health Care Delivery

\section{References}

1 Siegel RL, Miller KD and Jemal A: Cancer statistics, 2019. CA Cancer J Clin 69(1): 7-34, 2019. PMID: 30620402. DOI: 10.3322/caac. 21551

2 Gaitanidis A, Alevizakos M, Tsalikidis C, Tsaroucha A, Simopoulos C and Pitiakoudis M: Refusal of cancer-directed surgery by breast cancer patients: Risk factors and survival outcomes. Clin Breast Cancer 18(4): e469-e476, 2018. PMID: 28784267. DOI: $10.1016 /$ j.clbc.2017.07.010

3 Tohme S, Kaltenmeier C, Bou-Samra P, Varley PR and Tsung A: Race and health disparities in patient refusal of surgery for earlystage pancreatic cancer: An ncdb cohort study. Ann Surg Oncol 25(12): 3427-3435, 2018. PMID: 30043318. DOI: 10.1245/ s 10434-018-6680-6

4 Coffman A, Torgeson A and Lloyd S: Correlates of refusal of surgery in the treatment of non-metastatic pancreatic adenocarcinoma. Ann Surg Oncol 26(1): 98-108, 2019. PMID: 30145650. DOI: 10.1245/s10434-018-6708-y
5 Bilimoria KY, Stewart AK, Winchester DP and Ko CY: The national cancer data base: A powerful initiative to improve cancer care in the united states. Ann Surg Oncol 15(3): 683-690, 2008. PMID: 18183467. DOI: 10.1245/s10434-007-9747-3

6 Dominici L, Najita J, Hughes M, Niland J, Marcom P, Wong YN, Carter B, Javid S, Edge S, Burstein H and Golshan M: Surgery of the primary tumor does not improve survival in stage iv breast cancer. Breast Cancer Res Treat 129(2): 459-465, 2011. PMID: 21713372. DOI: 10.1007/s10549-011-1648-2

7 Puts MT, Tapscott B, Fitch M, Howell D, Monette J, WanChow-Wah D, Krzyzanowska M, Leighl NB, Springall E and Alibhai SM: A systematic review of factors influencing older adults' decision to accept or decline cancer treatment. Cancer Treat Rev 41(2): 197-215, 2015. PMID: 25579752. DOI: 10.1016/j.ctrv.2014.12.010

8 Puts MT, Tu HA, Tourangeau A, Howell D, Fitch M, Springall E and Alibhai SM: Factors influencing adherence to cancer treatment in older adults with cancer: A systematic review. Ann Oncol 25(3): 564-577, 2014. PMID: 24285020. DOI: 10.1093/ annonc/mdt433

9 Islam KM and Wen J: Prostate cancer patients' refusal of cancerdirected surgery: A statewide analysis. Prostate Cancer 2015: 829439, 2015. PMID: 25973276. DOI: $10.1155 / 2015 / 829439$

10 Wang $\mathrm{J}$ and Wang FW: Refusal of cancer-directed surgery strongly impairs survival of patients with localized hepatocellular carcinoma. Int J Surg Oncol 2010: 381795, 2010. PMID: 22312489. DOI: 10.1155/2010/381795

11 O'Connell JB, Maggard MA and Ko CY: Cancer-directed surgery for localized disease: Decreased use in the elderly. Ann Surg Oncol 11(11): 962-969, 2004. PMID: 15525824. DOI: 10.1245/ASO.2004.03.052

12 Yilmazer N, Aydiner A, Ozkan S, Aslay I and Bilge N: A comparison of body image, self-esteem and social support in total mastectomy and breast-conserving therapy in turkish women. Support Care Cancer 2(4): 238-241, 1994. PMID: 8087442 .

13 Khan S, Khan NA, Rehman AU, Khan I, Samo KA and Memon AS: Levels of depression and anxiety post-mastectomy in breast cancer patients at a public sector hospital in karachi. Asian Pac J Cancer Prev 17(3): 1337-1340, 2016. PMID: 27039768. DOI: 10.7314/apjcp.2016.17.3.1337

14 Newman LA and Kaljee LM: Health disparities and triplenegative breast cancer in african american women: A review. JAMA Surg 152(5): 485-493, 2017. PMID: 28355428. DOI: 10.1001/jamasurg.2017.0005
Received July 10, 2019

Revised July 29, 2019

Accepted July 30, 2019 